$8-2013$

\title{
Military nurses caring for the enemy
}

Sharon Thompson

University of Texas at Tyler

Beth Mastel-Smith

University of Texas at Tyler

Gloria Duke

University of Texas at Tyler

Barbara K. Haas

The University of Texas at Tyler

Shellye Vardaman

See next page for additional authors

Follow this and additional works at: https://scholarworks.uttyler.edu/nursing_grad Part of the Nursing Commons

\section{Recommended Citation}

Thompson, Sharon; Mastel-Smith, Beth; Duke, Gloria; Haas, Barbara K.; Vardaman, Shellye; and Yarbrough, Susan, "Military nurses caring for the enemy" (2013). Nursing Theses and Dissertations. Paper 76.

http://hdl.handle.net/10950/593 
Author

Sharon Thompson, Beth Mastel-Smith, Gloria Duke, Barbara K. Haas, Shellye Vardaman, and Susan Yarbrough 
Military nurses caring for the enemy

Author Note

Sharon Thompson served as an Air Force nurse during Operation Iraqi Freedom. This study was to be her dissertation; however, she passed away on Veteran's Day, 2011, before data collection began. Sharon's faculty and student colleague completed the study on her behalf: Beth MastelSmith, Sharon's Dissertation Chair, College of Nursing, The University of Texas at Tyler; Gloria Duke, College of Nursing, The University of Texas at Tyler; Barbara Haas, College of Nursing, The University of Texas at Tyler; Shellye Vardaman, School of Nursing, Troy University, Troy, Alabama; and Susan Yarbrough, College of Nursing, The University of Texas at Tyler.

Susan Yarbrough is now at the College of Nursing, Texas A \& M Health Science Center, Bryan, Texas.

The research was completed in Sharon's memory. Dr. Thompson was awarded her doctoral degree posthumously from The University of Texas at Tyler. The authors also recognize and gratefully appreciate participants' efforts in sharing their stories. No funding was received in support of this study.

Correspondence should be addressed to Beth Mastel-Smith, 406 Lovett Houston, TX, 77006. Email: bethms@swbell.net. 
Sharon Thompson, RN, PhD (deceased)

Beth Mastel-Smith, RN, PhD (corresponding author)

Associate Professor, College of Nursing

The University of Texas at Tyler

Tyler, TX

406 Lovett

Houston, TX 77006

Phone: $713-416-5690$

Email: bethms@ @wbell.net

Note: Because I telecommute, please send all correspondence to my home address. Thanks!

Gloria Duke, RN, PhD

Associate Dean for Research, College of Nursing

The University of Texas at Tyler

Tyler, TX

Barbara Haas, RN, PhD

Associate Dean for Graduate Studies, College of Nursing

The University of Texas at Tyler

Tyler, TX

Shellye Vardaman, RN, PhD

Assistant Professor, School of Nursing

Troy University

Troy, AL

Susan Yarbrough, RN, PhD, CNE

Associate Dean for Academic Affairs, College of Nursing

Texas A\&M Health Science Center

Bryan, TX 


\begin{abstract}
Purpose: This phenomenological study described the lived experience and aftermath of U.S. military nurses assigned enemy detainees during Operation Iraqi Freedom/Operation Enduring Freedom. Two themes emerged: Insurgent Assignments (subthemes included identification of and interactions with insurgents; training, precautions, and ethical issues, thoughts and feelings, coping, and meanings of insurgent care) and The Aftermath (subthemes were mental, emotional, personal, professional, and positive). Conclusions: Insurgent assignments caused ethical dilemmas and challenged theoretical constructs related to caring. Formal training is needed to prepare nurses for the practicalities of and responses to insurgent assignments.
\end{abstract}

Keywords: nursing, caring, ethics / moral perspectives, phenomenology 


\section{Military nurses caring for the enemy}

Thousands of military nurses have been deployed in medical support of combat troops during America's war on terrorism. In studies of military combat nurses, there are some common themes: emotional effects, preparedness issues, the combat experience, importance of relationships, and meaningful contributions (Baker, Menard, \& Johns, 1989; Krischke, 2008; Nayback, 2009; Scannell-Desch \& Doherty, 2010). In prior studies of military combat nurses, caring for the enemy is mentioned as a duty requirement, without details into the experience or effect on those nurses. Eight short narratives about caring for enemy insurgents are presented in Scannell-Desch and Doherty's (2012) timely book about military nursing. Issues included preparation for of insurgent care, cultural differences, working in an environment that included guards, and positive experiences. Nurses related that they had to focus on procedures to forget who the insurgent patient was, what the patient was accused of, and the inability to develop relationships with insurgent patients. Responses to providing insurgent care included fear, anger, nervousness, and the lack of feedback. There is no summary discussion about nurses' experiences of insurgent care; therefore, it is unclear if data saturation was achieved and if narratives were universal experiences of all participants.

No research was discovered that described the impact of caring for the enemy on U.S. military nurses. The study was originally conceived by an Air Force nurse who had been deployed to Iraq and her experiences guided the research question. Dr. Thompson was particularly intrigued by the concept of nurses 'caring' for the enemy within a context of 'caring' as defined by Watson (2008). Two weeks after successfully defending her proposal, she was diagnosed with pancreatic cancer and passed away on Veteran's Day. Her dissertation chair, faculty, and student colleagues completed the research on her behalf. The purpose of this study 
was to describe the lived experience and aftermath of U. S. military nurses who cared for enemy detainees while deployed in support of Operation Iraqi Freedom/Operation Enduring Freedom (OIF/OEF). This knowledge can be used to help nurses understand and prepare for deployment, guide pre-deployment training, and add insight for civilian nurses caring for societal 'enemies.'

\section{Methodology}

A descriptive phenomenological method of inquiry was used to investigate the experiences of U.S. military nurses who cared for enemy detainees, a topic about which little was previously known. Phenomenology, defined by Husserl (1970), is "the science of essence of consciousness" that reveals humans' reality and personal meaning. It aims ". . . to bring these (events) to complete clearness ... subject them to analysis and ... follow up the essential connections that can be clearly understood ..." (Husserl, 1952, p. 174). Attentively listening to and interacting with participants leads to an understanding of a person's experience. The ultimate goal is to develop a universal description of the phenomenon (Tymieniecka, 2003).

The research questions were: (a) What is the lived experience of caring for the enemy on U.S. military nurses who have been deployed in support of OIF/OEF? and (b) What is the aftermath of caring for the enemy on U.S. military nurses who have been deployed in support of OIF/OEF?

The University's Institutional Review Board approved the study, and participants provided signed informed consent. Telling stories about combat experiences had the capacity to evoke high-level emotions, stress, and memories of traumatic experiences. Mental health brochures from the Veterans Administration, the Center for Women Veterans, and the National Center for PTSD (post-traumatic stress disorder) were shared with the participants who 
expressed appreciation for the resources. If participants showed signs of distress during the interview, they were asked if they wanted to stop and continue at a later time.

Recruitment via word of mouth and snowball sampling continued until data saturation was achieved. The sample consisted of seven women and three men. The average age was 43 and ranged from 34 to 60 years. Most participants were White $(n=8)$, one was Hispanic, and one African-American. Six were in the Air Force, and the remainder was Army personnel. At the time of deployment, which ranged from 2003 to 2011, eight participants were active duty and two were reservists. Three nurses had bachelor's degrees, and the rest had masters' preparation. Four had been deployed more than once.

Interviews, which lasted between 35 minutes and one and one half hours, were audio recorded, transcribed verbatim, and verified by the researcher. An interview schedule consisting of open-ended questions began generally; "Tell me about your deployment” and became more specific, "What were your experiences caring for enemy detainees?" and "What did it mean to you to care for enemy detainees?" Probes elicited more detailed information. Participants' were located in diverse places; therefore, interviews were completed over the phone $(n=9)$ or using the software application Skype $(n=1)$.

Colaizzi’s (1978) seven steps guided data analysis. These included: (a) reading and rereading transcripts to ensure accurate understanding, (b) identifying significant statements, (c) articulating meaning for each statement, (d) categorizing meanings into clusters of themes and validating with transcripts, (e) integrating the clusters into a description of the phenomenon, (f) participant review, and (g) incorporating participants' suggestions into a final description. Tree nodes within NVivo software were created to organize similar clusters of data. 
Credibility is concerned with establishing the researcher's trustworthiness (Munhall, 2007) and was achieved in several ways. Transcripts were coded by two experienced qualitative researchers, discrepancies discussed, and data re-assigned to categories. Transcendental subjectivity through bracketing allows the researcher to set aside preconceptions and describe the universal phenomenon (Husserl, 2001). The primary investigator documented field notes and kept a journal of thoughts, perceptions, and responses before and during the interview and data analysis processes. Researchers involved in data collection or analysis had no combat or deployment experiences minimizing potential bias. Member checks were performed to determine the accuracy of the findings. A summary was shared with three participants; two responded with clarifications and additional information that were incorporated into the final manuscript.

\section{Findings}

In response to the research questions, two overarching themes and several subthemes emerged from the data. See Table 1.

Because interviews were conducted over the phone, researchers were unable to observe some non-verbal communication. However, certain cues were noted. Several participants cried or paused while sharing stories about insurgents. It was clear that remembering these situations was emotionally difficult. Although asked if they wanted to take a break or continue later, all completed their interview at the originally agreed on time.

\section{Research Question / Theme 1: Insurgent Assignments}

Training related to insurgent patients. Nurses were asked to describe the training received in preparation for insurgent patient assignments. One nurse explained,

My own naïve conception of what I was going to be doing. I didn't realize I would to be taking care of insurgents. I thought I was going to take care of coalition troops, the US 
forces, and our allies. It was quite shocking when the first patient I took care of was an Iraqi insurgent.

Another participant stated,

I don't ever recall anyone teaching me how to take care of a combatant. I had training how to take care of polytrauma patients but as far as an enemy was concerned, I don't remember ever getting that. The first one that I got [insurgent patient] on the plane I was like, "Oh my gosh...oh my gosh...ok - this guy shot that guy and that guy over there is dead."

Some nurses had no training; others were merely informed they would be assigned insurgent patients, while still others were told they would only be assigned American personnel.

One participant reflected back to her nursing education that was "quite sensitive to codes of nursing where we practiced ethically and not in a biased manner when we're approaching our patients." Every participant explained that the military reinforced this ethical code:

We had mobility training ... it talks about your role as a non-combatant . . The expectation is you are caring for the enemy injured just the same as you would for our own ... the Geneva Convention [states] you care for them without bias.

Participants believed that they and their colleagues had given insurgent patients "the best care possible" and had not "skimped on anything."

Some nurses had training related to the Iraqi and Afghani cultures. These included “. . . short religious and political backgrounds, country history" and "language." The military provided education for two participants regarding nurses' responsibilities when assigned blindfolded and restrained insurgent patients. In addition, safety precautions such as "not wearing a stethoscope hanging around your neck because it could be used as a choking device" 
were shared. Participants felt more education was needed regarding personal safety. One nurse stated, “. . . they really need to educate people that they still could be harmed or assaulted ... more situational awareness." The need for education in areas such as patient care processes and emotional responses to insurgent patients was also voiced. "I would say we didn't have a process when I got there in terms of how we were gonna provide care to them and maintain any security" explained one nurse. Another volunteered, "If someone could have told me how I was going to feel inside: 'If you do anything I'm going to try to beat you to death', while you're supposed to be this compassionate nurse."

Identification of insurgent patients. One challenge was actual identification of insurgents. "The most confusing part about taking care of Iraqis was not really knowing who was an enemy." Two participants offered, "I think that was a lot fuzzier than people realize because we would hear stories about civilians who would lay out IEDs or be martyrs and wear bombs" and "... even children would be carrying weapons."

Not knowing who the enemy was, nurses “. . . were trained to check Iraqis for weapons”. "You hoped that had been done ahead of time before they came in, but you don't want to assume so we always typically removed uniforms and clothes and checked for weapons as part of the initial assessment." When assessing a traditionally-clothed woman, one nurse made a surprising discovery: "I gave her a full pat-down looking for weapons . . . Now in my pat-down I examined her abdomen and I realized she was 8 months pregnant!"

Once identified, insurgent patients were assigned an "enemy number"; "So when you came on shift you were supposed to know which ones were 'enemy' and which ones were 'good guys." This practice was not always reliable. When an unconscious patient's designation was changed overnight, the nurse asked, "How do you guys decide whether these guys are good guys 
or bad guys? They all dress alike, there's no outward sign that he is a good guy or a bad guy." [Security forces] said, "Oh, we ask them."

Interactions with insurgent patients. Insurgent patients' attitudes and behavior varied. "If they [insurgent patients] were in duress, they were pretty complacent or cooperative." Some were "passive or ignored you," others were "hostile and aggressive," or ". . . had this resolve the whole time, sort of flat, emotionless, didn't ask for anything, very low maintenance. Very quiet and seemed maybe even perhaps suspicious of some people." One insurgent patient was described as ". . . belligerent as all get-out ... He would do everything he could to anger the nurses: he would spit at them, curse at them, he wouldn't do anything he needed to do to get better." Nurses reported that some insurgent patients would try to hit, bite, and kick them. One insurgent patient said, "I am pure Al Qaeda, I hate your guts. I will kill you in a heartbeat." Insurgent patients' attitudes and behaviors affected nursing. Nurses reported giving "the basic package of good patient care." Another nurse explained, "It's basically straight forward, provide the care, treat 'em all as a patient and then go from there. But as far as like conversations you may have with other patients—-that's not allowed."

Communication with insurgent patients was a challenge for a variety of reasons. Language was one barrier. One nurse said, "What I personally do is break it down to the basics: hand language, sign language, or basic things like food, bathroom, things of that nature, pain ... make it simple and cut out the complex things.” Another participant, “. . . learned a little bit of Arabic just enough to basically get them to cooperate." While interpreters were available, it “. . . was a small population to assist you." Translators explained nursing procedures as well as intent but also caused unease: "Your concern is always, did the interpreter give them the right information or are they calling them bad names between everything else?" Guards also knew 
"enough of the language to at least get the gist of what they were saying. Another barrier to communication was the inability to use visual cues such as a pointy-talky, a visual language aide, when an insurgent patient was blindfolded. Communication barriers affected nursing care. One nurse explained, "A lot of the care you deliver is mechanical . . . very task oriented ... it's difficult to be nurturing to someone when you can't communicate with them."

Adult insurgents and children suspected of actions against American personnel were sometimes treated differently. Nurses deployed early in the war "quickly realized it was not a good set-up" to have "... an American soldier lying next to an Iraqi soldier." They "found a way to block them off from the rest of the people for security purposes. So we would have to hang sheets from the top of the tent." In fixed facilities, American personnel and Iraqi police were assigned one hallway and insurgents and civilian Iraqis another hallway. If the insurgent patient was very hostile, they would be placed in a private room. While adults suspected of being enemy insurgents were kept under high security, younger children alleged to have been involved in setting up IEDs were treated, "much differently than we would have treated any suspected detainee as an adult." One nurse said, "I had to care for a girl who was no more than 12-13 years old with restraints and a blindfold. Not one of my prouder moments; it made me sick to think about applying these rules to a child."

Precautions. Insurgent patients were "brought in in shackled, handcuffed, and blindfolded" and during air transport were shackled to the floor of the plane. They were blindfolded, “. . . because of the high risk of them recognizing faces and voices and being able to target the staff" as well as Iraqi interpreters. "Our interpreters took high risk coming to work for the Americans, so if we got a detainee or POW that recognized one of the interpreters they could target their family." "Interpreters also had fake names so if someone mistakenly called them by 
name, the insurgent wouldn't know who they really were," added another nurse. For this reason, nurses covered their name patch and did not, "call each other by name" to prevent identification. They did not, “. . . make any references to the day of the week or the hour . . . talk about anything at home ... friends or family or anything like that."

Insurgent patients were under guard. "You could signal them [a guard] that someone was being inappropriate and they'd be right there Johnny-on-the-spot." While providing nursing care, “. . . there's a guy with big guns standing beside me-M16s, 9mms; they have several guns on each of them." One nurse said, "It was nerve-wracking."

Although security precautions were in place, nurses were sometimes uncomfortable delivering care to insurgent patients. You, “. . . always kind of have your guard up" and “... don't assume that anybody is completely safe ... something you have to have in the back of your mind." Certain insurgent patients put the nurse "on alert." In one case, a nurse had to give up her gun because she feared that the insurgent patient would grab it and use it against her and the American crew.

Ethical issues. Insurgent patient assignments presented "a lot of ethical dilemmas." The provision of unbiased care to people who had potentially harmed colleagues was shared: "I was torn between the fact that here lies someone who is trying to kill my troops, my soldiers, my colleagues. Now I'm faced with having to provide the care that any human deserves." Nurses questioned care of insurgents for a variety of reasons: "These people are the enemy, why are we doing this, why are we treating them, why are we making them better?" The use of American resources was an ethical issue for participants: "We spend time, a lot of effort, blood, sweat, and tears ... a lot of physical resources" and “... multimillion dollar care to enemy insurgents.” One nurse said, “. . . it would have been more humane to let some of these people go." Another 
offered, "Someone needs to teach the security forces to go for center mass and stop shooting them in the head because they just end up ... comatose and unresponsive, and with very little chance of recovery." When an insurgent patient, “... would do everything he could to anger the nurses," this too caused the nurses to wonder, "Why are we doing this?" Iraqi health care resources were inadequate to care for casualties of war which further complicated nurses' response. One nurse had the opportunity to assess an Iraqi hospital and shared, “. . the conditions of these Iraqi hospitals was very scary ... to take care of these patients and have to discharge them back to these Iraqi hospitals where God knows if they got adequate care was stressful." Of note, “(Insurgents) did not stay with us very long ... we were basically a stabilize and ship facility.”

Issues of death and dying also posed challenging situations related to unbiased care. After the ethics board decided to terminate life support for a futile case of an insurgent patient, one nurse shared, "I had conversations with the chaplain and he summed the way I felt by saying, 'I sit here and I pray and I pray. How do I pray for a peaceful death for my enemy?'” At the same time, nurses felt, “... we need to show the respect for life that we would hope they would show to our troops should they be injured and captured by the enemy."

Guards and colleagues of injured American personnel created ethically challenging situations for some nurses. As one nurse explained, The guards were upset with what they [the insurgent patient] had done ... I'm having to go into a room and take care of somebody who is responsible for killing people ... it's hard when these buddies are trying to support each other. . I have a responsibility to this person [the insurgent patient] but I also had a responsibility to the Americans and trying to be compassionate and understand what they are feeling. I don't think you can ever do 
the right thing because I don't know what the right thing is. How do you explain to a young, 18-year-old kid, "Your buddy died because of this woman?"

At times guards intruded in patient care with statements such as, "You know he doesn't need pain meds, you know he's hurt our people" which was "difficult [for the nurse] to deal with."

A unique ethical situation related to the patient who hid a child under her robes while detonating a bomb near U. S. troops. Because she was a suspected insurgent patient, she should have been restrained. The nurse said,

... but she also needs to take care of her child because it's not like there's social services that can come in and take these kids into a foster care situation so you are forced to deal with an adult who is injured and a child until they can figure out what to do.

Thoughts and feelings about insurgent patients. Participants were asked to share thoughts and feelings they had when caring for insurgent patients. "I felt like it was an obligation. I took my role under the Geneva Convention pretty seriously 'cause I felt like it was important for me to protect that right to be a non-combatant" stated a participant. Another said, "There was a certain responsibility and accountability there." One nurse explained it this way, “...you do it the best you can ... that's just the mindset if you're a nurse, you take care of whoever needs help.”

Insurgent patients' actions, perceived potential or real threats toward American troops and nurses themselves prompted various responses. One participant said, “... for the most part we carried the mindset that 'innocent until proven guilty' ... it's not our job to decide." Some nurses admitted feeling bias against insurgent patients who were suspected of injuring American personnel: "As neutral as you try to be, you know you have underlying feelings about who you 
are taking care of." A participant compared and contrasted experiences before and during deployment. She said,

Prior to that experience I don't think I had ever at least acknowledged any sort of xenophobic feelings of anger toward an entire population or group of people. That's the year [of deployment] it became really difficult to not have the feeling surface ... my life outside of Iraq has sheltered me enough from those feelings. I understand the human process of harboring that; the anger and the resentment toward the group if you are constantly exposed to it.

Another participant explained, "When you take care of somebody that you know is out there potentially killing US service members, there is a degree of resentment that you are wasting your resources and time on those people." "It frustrated me that we were spending our resources on them", one nurse said. Some nurses became, “. . . less tolerant and empathetic of the detainees, especially if they had dealt with them many times before from multiple deployments" or "as the year went on ..." Combative insurgent patients caused emotional responses. "I didn't necessarily feel unsafe but there's just a certain level of irritation with somebody trying to assault you.” Another nurse was fearful when an insurgent patient became combative: “. . at any moment the side rail . . could come undone or the restraint could tear off leaving me vulnerable ... with one swing I'd be out."

Anger was another feeling experienced by the nurses. "I was really angry. Much angrier than I thought I would be. Because they knew that he was an insurgent and here we are taking care of him and he's killing our people." In one case, a toddler hidden underneath a suspected insurgent's robes during a bombing was admitted with the injured insurgent. The nurse remembered feeling very angry at the women for putting a child in such danger. 
Nurses talked about having to hide their feelings. One nurse noted,

Some days I dealt with anger, I dealt with pure rage but I had to control it because I . . . had to do my ... job to my best ability in spite of what this bastard did to American soldiers ... I had to shut off those emotions.

Another said, "I'm sure I had those feelings but I would just try not to make . . . a hasty assumption; that I didn't know the whole story and this person has not gone through a trial yet." Feelings of conflict were also reported. While caring for an insurgent patient, a nurse remembered,

As nurses we say, "do no harm" and we do our very best when you put your uniform on and go to work to take care of patients ... I'm going to give you this morphine and I'm going to take care of you but if you do anything, I will pummel you in the face.

Now... who says that? Who says that? Who says that about a patient? I just don't know how you feel those things all at the same time. And it feels bad to think that about another human being but I know that he'll kill me in a minute if he could get his arms around me. While transporting an insurgent patient, a nurse had to ensure the safety of the entire crew. This meant giving orders to Army guards, tired from days without sleep, to secure the environment. She said, "A lot of internal conflict because I'm feeling like, 'Oh I'm being an ass,' but I'm really trying to make sure my patients and my crew are safe ... we could all die."

Sorrow and sadness were also experienced by nurses caring for insurgent patients. One story continues to haunt a nurse who cried as she described an insurgent patient whose condition had stabilized and was being transported out of the hospital:

$\ldots$ he needed to be blindfolded to walk out of the hospital ... I explained ... what was happening and why we were doing it and this man began to shake violently. I kept telling 
the translator, "Make sure he knows that we're not going to hurt him" .. . The translator kept telling him, “It's OK, we're not going to hurt you; we're not going to hurt you." He kept saying, "OK, OK, OK" ... he tripped on the tent flooring. He was so panicked at that point he kept telling the translator I'm not trying to run away. It was obvious that he was expecting that we would be taking him out to kill him or shoot him . . . this person probably knows nothing else except this very violent, very cruel, war-ful life and it was very sad to see that.

A nurse also reported feeling sorrowful about casualties of war:

The emotion that constantly rises up is the feeling of sorrow. I felt sorrow all the time ... my question was, "What was their quality of life going to be years later, months later? How are they going to rehabilitate?". . there was this profound sense of sorrow dealing with how this person was going to adapt to their new life.

Coping. Nurses identified several coping mechanisms used when caring for insurgent patients. Some focused on the job that had to be done and, “. . . blocked out that part of it that this is somebody who has done bad things to people in general." One nurse said, "You put a blanket over his head ... I have these feelings and I need to put them away ... and you need to [do] what's required to stabilize this person." A participant used self-talk to cope:

You have to keep yourself positive and you have to keep up. Otherwise you can't function. So I would think, "I'm ok" and tell myself "I'm ok and nothing's going to happen to me. I have these guys right here and they're going to protect me." Others credited their support system, life experiences, and ability to put "what you've seen behind you and move on" with maintaining their mental health during and after deployment. 
Meaning of insurgent care. Participants were asked what it meant to them to care for insurgent patients. Meaning frequently related to their role as a nurse, "You just got to go into every situation with an open mind. Your job is to provide adequate healthcare." Another confirmed, 'If I made a difference in someone's life whether he's an insurgent who's now gonna be able to keep his leg because we did all the right things, then that's what I'm supposed to do." Ramifications of healing the enemy were also shared: "It meant that we're just going to fix them up and ... they get another opportunity to shoot at us . . kill another one of our beautiful airmen, army, navy, or marine guys.” In contrast, another stated that it was an opportunity to, “. . . showcase the humanity of the American culture . . and hopefully leave a positive impression." Participants commented on how insurgent care brought meaning to their humanness or personhood. "We are all human and vulnerable from time to time, and we hope that there's someone there to help us when we are vulnerable, that will provide what we need to help us get back to a healthy state" said one nurse. Another responded,

My belief is that there are no ordinary moments and that you are being groomed for something else down the road of your life and so I know that these profound, horrific, saddening events ... will benefit my life somehow later down the road.

\section{Research Question / Theme 2: The Aftermath}

Because combat nursing and caring for insurgent patients occurred simultaneously, it is difficult to attribute effects to one or the other exclusively. Effects were mental and emotional, personal, professional, and positive.

Mental and emotional effects. Nurses reported a numbing that occurred: “. . . when you take on that much trauma on a consistent basis, your mind eventually becomes very, very numb and you just become very robotic. You just do what you got to do to get this patient stabilized." 
When she returned home, a participant was told, "You don't react" as expected to situations. She believed this was a way of "insulating" herself from "an emotional response" and that this was the result of "having multiple traumatic events whether it be in a combat zone or otherwise." One nurse, diagnosed with post-traumatic stress disorder (PTSD), related a traumatic experience and said, "I never reacted to another person again . . . whether they be Iraqi or be American I just never cared after that." He "socially isolated" himself and "contemplated suicide" but has not "acted on it." He "lives as normal life as I can" and experiences . . . times when I do what I call 'freak out' ... it hits and I don't know when it's going to hit." The participant vowed, "I still want to remain a soldier, I want to remain a nurse, a very good nurse. I know because of my experiences that I am a stronger person. I am a very good healthcare provider.” Another nurse acknowledged that it took time before she was able to discuss the effects deployment to a combat zone had on her:

I sucked it up and I was absolutely miserable and no one knew. I think I probably selfmedicated with a little bit too much alcohol at the time ... truthfully [it was] two and a half years before I could even go and say anything to anybody ... It's only been within the last year that I actually went and said, "I'm very sad and I need help."

For those who struggled with the haunting effects of deployment, obtaining help on return to the US was difficult for various reasons. Participants felt that they "should be strong enough to hold it together." There was a perceived threat that if found to have mental health problems, the nurse might be relieved of their duties. This in turn to added "a lot of pressure" because the nurse, “didn't want to have my buddies [do] extra time because I can't go.” 
Effects on personal life. Deployment affected participants' personal lives. As one nurse explained, “As a person it's made me more appreciative of what I have. I have a good family that raised me, loved me, fed me, and clothed me." Awareness translated into action for one person: I saw over there [Iraq] mothers that would come in and hoard food under their gowns ... because they had nothing ... Now, I buy food for the food bank [in US] just because there are people in our own country that don't have anything. I am much more apt to do chartable kinds of things ... I feel the need to help people.

For two nurses, their attitudes were affected by combat experiences. One said, "I don't sweat the small stuff."

After deployment to a combat setting, "integration back in with your family and finding out what your role is" was challenging for nurses. Even the simplest tasks were a challenge, I was just dying because I was like, “Are you kidding me?” I didn’t even know how to make the flippin' salad! I don’t know if it was because my mind was so consumed with everything, but it was tough.

Combat situations were described as other-worldly: "You feel like you're on Mars. You've been away from normal life for so long you don't even remember it anymore."

Effects on professional life. The combat experience provided professional rejuvenation. One nurse said, Before I deployed, I didn't want to be a nurse anymore. I was burnt out, hated it, didn't enjoy it ... when I came back it gave me the sense of renewal and excitement ... like when I first graduated from nursing school. This is why you became a nurse . . . and [it] made me a better human being. 
A nurse applied a moral code similar to that used when caring for insurgent patients in the context of current advocacy efforts,

... how do we treat pregnant women? ... in the prison system or during labor and delivery, should they be restrained? Do they get to hold their baby afterwards? . . . what are the rights of the mother who's maybe murdered somebody? Of course, I'd take the right preventative precautions but they deserve the same treatment that anybody else does. You're not gonna tell this woman (prisoner), "You know, you don't get an epidural because what you did is really bad." I can be a better advocate in that perspective.

Participants felt combat nursing enhanced their nursing skills. "It really forced me to look back at what I had learned many, many years ago and that I really hadn't put into practice . . . and I think that's what made me a better nurse" one stated. Another said, "[The experience] has driven my professionalism as a nurse."

Positive experience. Most participants felt deployment and caring for insurgent patients were, while difficult, positive experiences. Two talked about the satisfaction they felt. One described,

... you get a lot satisfaction out of what you are doing ... it's unlike anything you'll ever experience in the US ... to be able to utilize my experience in that capacity and to take it to people who will likely never have it again is very gratifying.

A nurse felt that the collegial relationships formed helped define the experience: "We bonded ... We were so dependent on each other to get it done that it creates very intense bonds."

\section{Discussion and Recommendations}

Ten Army, Air Force, active duty, and reservists’ perceptions comprise the findings. Limitations include a small sample with a wide range of ages, varying numbers, and year of 
deployment. Participants included both active military personnel and reservists and represented just two branches of the military. Therefore, other perceptions are not represented, and findings are not generalizable. This limitation was mediated somewhat by the wide ranges of ages and diversity of experiences. In addition, given that the majority of the interviews $(n=9)$ were conducted over the telephone, most participants' facial expressions and other non-verbal cues were not visible to the researchers thus limiting interpretation of visual data. It is not known if a face-to-face interview would have stimulated further discussion or inhibited free expression without concern for being judged. One might argue the investigators' lack of military experience and understanding military hierarchy were limitations, potentially leading to passing judgment on the respondents' stories. However, the investigators' lack of experience was instead a strength in that there were no preconceived ideas about what it was like caring for enemy insurgents.

Study findings are both similar and dissimilar to previously reported narratives about insurgent care during OEF/OIF (Scannel-Desch \& Doherty, 2012). In contrast to most participants in this study who had little to no preparation, at least one nurse (Scannel-Desch \& Doherty, 2012) received training for insurgent care. Consistent with the previous report (Scannel-Desch \& Doherty, 2012), nurses experienced hatred from insurgents and were angry, fearful, or nervous about having to care for insurgents and did not trust this patient group. Unlike previous accounts (Scannel-Desch \& Doherty, 2012), nurses in the current study did not experience expressed appreciation from insurgent patients and felt threatened when caring for insurgent patients. In both the current study and previous narratives, nurses attempted to disassociate the insurgent patient from what the patient was allegedly accused and viewed insurgent patient care within the greater human context. Nurses were conflicted about a variety 
of moral and ethical issues related to insurgent care some of which remain unresolved including the role of the nurse to be compassionate yet ready to defend her life if necessary. These findings support Kelly's (2010) interpretative research approach to the ethical and legal literature surrounding nursing in battlefield conditions. Although Kelly does not directly address insurgent assignments, she points out that nurses experienced dual loyalty conflict; "that is that of soldiers/nurses having to obey military orders while also having to follow professional codes of practice" (p. 642). Current participant accounts also reflect previously reported narratives (Scannel-Desch \& Doherty, 2012): forming nurse patient relationships with insurgent patients was not possible, patient care was provided in the presence of armed guards and to blindfolded patients, and nurses wondered about the fate of patients on discharge. Two nurses in the current study shared struggles with psychological disorders and reintegration following deployment. These experiences are congruent with previous research that reported combat increased mental health illnesses (Gibbons, Hickling, \& Watts, 2012) and difficulty with reintegration (Boyd, Bradshaw, \& Robinson, 2013) among military healthcare personnel. Themes derived from a historical study of nurses caring for American personnel during the Persian Gulf Wars included, “It's what we're here for", sacrificing physical safety, and professional commitment (Rushton, Scott, \& Callister, 2008) all evident in current findings.

During conceptualization of the study, discussions often turned to whether care was provided to insurgent patients as defined by Watson's (2008) Caritas Processes. In Table 2 the CARITAS Processes and evidence or propositions that support or are contrary to realization of each process are presented. While acts of care might have occurred, current data suggests that care according to CARITAS Processes was not delivered. Even use of the word care which defines nursing actions, might cause stress and conflict for deployed nurses. Nurses have been 
socialized to care; however, insurgent assignments might preclude realization of that goal. Future research might investigate deployed nurses' definition of care and clarify the nurse's role in the context of insurgent assignments. This information could be shared with future deployed nurses and prevent conflict and stress. Results might also shed light on the relationship between care in this context and theoretical definitions and constructs.

Study findings suggest the need for improved training and preparation of deployed nurses. Insurgent patient care caused ethical dilemmas, various emotional responses, and internal conflict for deployed nurses. Some participants appeared to cope effectively while others were profoundly affected. Military nurses must receive formal preparation before deployment which might require insurgent patient care. Minimally, this training should include personal safety, ethics, self-care, working with translators and guards, and dealing with conflicting emotions and role identities specifically those of nurse and soldier. In addition, nurses' commitment to each other in stressful patient-care situations; and anticipating, mitigating, and surviving PTSD must be covered. Nursing school curricula and continuing education should focus on similar topics in the context of societal enemies such as gang members or prisoners. Post-deployment, nurses also require support. They need help reintegrating into society, accessing, and obtaining mental health services including counseling without fear of reprisal.

Future research might explore in greater depth nurses' combat and insurgent patient care experiences. Specifically, documentation of the ethical dilemmas nurses encounter and the impact these dilemmas have on patient care is needed. The effect insurgent care has on nurses' mental and physical health as well as professional practice should be examined. Investigating factors that impact nurse-patient relationships in non-traditional care settings may improve care 
delivery and salvage careers. Understanding self-care during deployment and the efficacy of identified practices would help personnel deployed in the future.

Nurses experienced conflicting feelings related to the nursing role and the reality of caring for or protecting themselves from insurgent patients. According to Watson (2008), a helping-trust relationship is necessary to achieve human caring. Participants described taskoriented care, distrust of insurgent patients, and the inability to form relationships with this patient group. These factors bring into question whether helping-trust relationships are possible with insurgent patients. If custodial services are provided in the absence of helping-trust relationships, is nursing care preformed? Theoretical applications should be explored in the context of patients that are societal enemies. Findings from these investigations might suggest a different paradigm of nursing, one that recognizes the potential for patient care in non-traditional circumstances and challenge constructs historically associated with caring. In addition, affirmation of nurses' contradictory responses and clarity to a revised role might be elucidated.

\section{Conclusions}

Participants' stories revealed much about insurgent patient care that was previously unknown to the general public and non-military health professionals. Nurses performed their duties in harrowing situations that most nurses will never experience or imagine. Participants were exposed to the worst atrocities of war yet underscored that insurgent patients were provided the best care possible. Two participants likened combat duty to that of working in an emergency room and caring for multi-trauma or societal enemies such as gang members. However, an austere and dangerous war zone creates additional layers of and greater stress for service personnel. The nurses' dedication and commitment to the nursing role and their country was 
obvious and awe-inspiring. As a profession we should express recognition of and affirmation for their tremendous contributions to all patients and their country. 
Acknowledgements: This study was completed in memory of Sharon Thompson, an Air Force nurse deployed during OIF/OEF and who initiated the research. Dr. Thompson was awarded her doctoral degree posthumously from The University of Texas at Tyler. The authors also recognize and gratefully appreciate participants' efforts in sharing their stories. 


\section{References}

Baker, R.R., Menard, S.W., \& Johns, L.A. (1989, Sept). The military nurse experience in Vietnam: Stress and impact. Journal of Clinical Psychology, 45(5), 736-744. doi:10.1002/1097-4679(198909)45:5<736::AID-JCLP2270450508>3.0.CO;2-M

Boyd, M. A., Bradshaw, W., \& Robinson, M. (2013). Mental health issues of women deployed to Iraq and Afghanistan. Archives of Psychiatric Nursing, 27(1), 10-22. doi: 10.1016/j.apnu.2012.10.005

Colaizzi, P. (1978). Psychological research as the phenomenologist views it. In: Valle, R., \& King, M. (Eds.), Existential Phenomenological Alternatives for Psychology (pp. 48-71). New York, NY: Oxford University Press.

Creswell, J.W. (2009). Research design: Qualitative, quantitative, and mixed methods approaches, $3^{\text {rd }} e d$. Thousand Oaks, CA: SAGE Publications

Gibbons, S. W., Hickling, E. J., \& Watts, D. D. (2012) combat stressors and post-traumatic stress in deployed military healthcare professionals: an integrative review. Journal of Advanced Nursing, 68(1), 3-21. doi: 10.1111/j.1365-2648.2011.05708x

Husserl, E. (1952). Ideas: General introduction to pure phenomenology (W. Gibson, Trans.). New York: Macmillan.

Husserl, E. (1970). Logical investigations (J. N. Findlay, Trans.). New York: Humanities Press.

Husserl, E. (2001). Analyses concerning passive and active synthesis: lectures on transcendental logic (A. J. Steinbeck, Trans.). Boston: Kluwer Academic.

Kelly, J. (2010). Battlefield conditions: Different environment but the same duty of care. Nursing Ethics, 17(4) 636-645. doi: 10.1177/0969733010373434 
Krischke, M. (2008). Army reserve nurse shares tales from Iraq. Nursezone. Retrieved from http://www.nursezone.com/nursing-news-events/more-features/Army-Reserve-NurseShares-Tales-from-Iraq_20294.aspx

Morse, J.M. \& Field, P. A. (1995). Qualitative research methods for health professionals, $2^{\text {nd }}$ ed. Thousand Oaks, CA: SAGE Publications.

Munhall, P. L. (2007). Nursing research: A qualitative perspective, $4^{\text {th }}$ ed. Sudbury, MA: Jones and Bartlett Publishers

Nayback, A.M. (2009). PTSD in the combat veteran: using Roy's Adaptation Model to examine the combat veteran as a human adaptive system. Issues in Mental Health Nursing, 30(5), 304-310. doi:10.1080/01612840902754404

Rushton, P., Scott, J. E., \& Callister, L. C. (2008). “It's what we're here for.” Nurses caring for military personnel during the Persian Gulf Wars. Nursing Outlook, 56(4), 179-186. doi: 10.1016/j.outlook.2008.03.010

Scannell-Desch, E. \& Doherty, M.E. (2010). Experiences of U.S. military nurse in the Iraq and Afghanistan wars. Journal of Nursing Scholarship, 42(1), 3-12. doi: 0.1111/j.15475069.2009.01329.x

Scannell-Desch, E. \& Doherty, M.E. (2012). Nurses in war. Voices from Iraq and Afghanistan. New York: Springer Publishing Company.

Tymieniecka, M. T. (2003). Introduction: Phenomenology as the inspirational force of our times. In M. T. Tymieniecka (Ed.), Phenomenology world-wide. Foundations-expanding dynamics-life-engagements. A guide for research and study (pp. 1-10). London: Kluwer Academic. 
Watson, J. (2008). Nursing: The philosophy and science of caring, revised edition. Boulder, CO: University Press of Colorado. 
Table 1

Major themes and subthemes

Theme 1: Insurgent Assignments

Subthemes:

Training for insurgent care

Identification of insurgents

Interactions with insurgents

Precautions taken while caring for insurgents

Ethical issues related to insurgent care

Thoughts and feelings about insurgent care

Coping with insurgent care

Meaning of insurgent care

Theme 2: The Aftermath

Subthemes:

Mental and emotional effects

Effects on personal life

Effects professional life

Positive effects 
Running head: NURSES CARING FOR THE ENEMY

Table 2

CARITAS Processes and insurgent assignments

CARITAS Processes as Defined by Watson Insurgent Assignment Support or Lack of Evidence (2008)

for Caritas Processes

1. "Practice loving kindness/compassion and equanimity with self and others.

2. Being authentically present; enabling, sustaining, and honoring the faith, hope, and belief system and inner-subjective world of self/other.

3. Cultivating own spiritual practices; beyond ego-self to authentic transpersonal presence.

4. Sustaining a loving, trusting, and caring relationship.
1. The data suggests that nurses felt compassion for enemy patients. Practicing loving kindness/compassion was not evident. Nurses expressed negative bias, frustration, and resentment about resources expended on, and anger towards insurgent patients.

2. One nurse shared the experience of sitting with an insurgent removed from life support because she did not want him to die alone. This suggests authentic presence. Other examples of insurgent assignments reflect fear, frustration, anger, and prejudice. Given these emotions one wonders if an authentic presence is possible.

3. Spirituality was not mentioned in relation to insurgent care.

4. Nurses were unable to develop caring relationships with insurgent patients for a variety of reasons including the inability to communicate, safety, fear, abuse from 
Running head: NURSES CARING FOR THE ENEMY

insurgents, and guard and American troop interference.

5. Allowing for expression of feelings; authentically listening and 'holding another person's story for them'.

6. Creative solution seeking through caring process, full use of self; all ways of knowing/doing/being; engage in artistry of human caring-healing practices and modalities.

7. Authentic teaching-learning within context of caring relationship; stay within other's frame of reference; shift toward a health-healingwellness coaching model.

8. Creating healing environment at all levels; physical/nonphysical, subtle environment of energy, consciousness, wholeness, beauty, dignity, and peace are potentiated.

9. Reverentially and respectfully assisting with basic needs, holding an intentional, caring consciousness of touching the embodied spirit of another as sacred practice, working with life force/life energy/life mystery of another.
5. Insurgent patients' feelings and stories were not encouraged because of language barriers, safety concerns, and disinterested patients.

6. Nurses provided basic care and did not view care as nurturing. Healing practices were limited by communication and superficial nurse-patient interactions.

7. Patient teaching was limited by language barriers and resources available upon discharge.

8. The goal of combat medicine was to stabilize and transport patients to other locations in Europe, the US, a local hospital, or jail. Stabilization of physical systems contrasts with holistic healing.

9. Nurses treated insurgent patients with respect; however, they also described providing basic, even mechanical, care. A deeper interaction with insurgent patient's embodied spirit was not evident. 


\section{Running head: NURSES CARING FOR THE ENEMY}

10. Opening and attending to spiritual, mysterious, unknown, and existential dimensions of all the vicissitudes of life, death, suffering, pain, joy, transitions life change; 'allowing for a miracle.' All of this is presupposed by a knowledge base and clinical competence".
10. Clinically, nurses provided some of the best medical care possible. It might be surmised that the vast cultural disparities and situational context posed barriers for nurse - patient spiritual connections. 


\section{Running head: NURSES CARING FOR THE ENEMY}

Word count (including references, acknowledgments, and tables; excluding abstract [91 words] and keywords [7]): 8116. 